\title{
As Bruxas no Divã: o desafio de ser criativo e ousar no ensino de artes
}

\author{
Márcio Luiz Bess
}

Marcelo Luis Rossa*

Tarcísio Vanzin $^{* * *}$

\section{Resumo}

Este artigo relata o projeto As Bruxas no Divã, que consiste na produção de um filme no Instituto Estadual de Educação (IEE), escola da rede estadual de ensino de SC. Nele introduziu-se a linguagem cinematográfica na Educação Infantil, contribuindo no processo de ensino e aprendizagem de Artes. O objetivo deste projeto foi desenvolver uma vivência dentro das diversas linguagens artísticas, como o teatro, as artes visuais, a música, a dança e demais ramificaçôes, bem como aguçar a reflexão sobre questôes existenciais da vida e potencializar os processos criativos. Para a realização do filme foram utilizados diversos saberes, bem como novas tecnologias, seguidas da observação e analise do aproveitamento que os alunos obtiveram nessa proposta de prática pedagógica. $\mathrm{O}$ elemento motivador dos pesquisados foi a literatura e a produçáo de cinema amador infantil, que comprovou ser uma forma de comunicaçáo apta a estabelecer interdisciplinaridade de várias áreas do conhecimento de forma criativa e harmoniosa.

Palavras-chave: Artes - Ensino. Cinema - Meios de Ensino. Desenvolvimento da Criatividade.

\footnotetext{
Mestre em Design Universidade Federal de Santa Catarina (UFSC). Professor de Artes do Instituto Federal de Santa Catarina (IFSC).

* Graduado em Comunicaçáo Social pela Universidade para o Desenvolvimento do Alto Itajaí - (UNIDAVI). Graduando em Psicologia pela mesma Universidade. Pós-Graduando em Marketing Digital pela Estácio de Sá.

${ }^{* * *}$ Doutor em Engenharia de Produção pela Universidade Federal de Santa Catarina (UFSC). Professor do Departamento de Engenharia do Conhecimento e dos Programas de PósGraduação em Engenharia e Gestão do Conhecimento e Pós-Graduação em Arquitetura e Urbanismo da UFSC.
} 


\section{Introdução}

A proposta de trabalhar a linguagem cinematográfica na Educação Infantil surgiu do desejo dos alunos e da necessidade de trazer para o ambiente de sala de aula conceitos e técnicas pedagógicas para contribuir com o processo de ensino e aprendizagem de Artes. Educadores frequentemente constatam que as crianças evoluem no seu aprendizado escolar quando motivadas, sendo que o interesse e a curiosidade devem ser despertados com esse objetivo. A absorção do conhecimento somente ocorre quando há interesse e compreensão do educando, deve instigar sua curiosidade. "O interesse permeia qualquer esforço e vem antes do aprendizado.” (WURMAN, 1991, p. 146).

Desenvolver novas formas de ensinar vem ao encontro das necessidades da atual prática de ensino/aprendizagem. Desta forma, o grande desafio do professor de Arte é romper com a generalidade amorfa da polivalência ${ }^{1}$ e tentar um trabalho aprofundado em uma das Artes, preferencialmente dentro de sua formação, mas sem cair na compartimentação dos conteúdos, sem deixar de ter como referência outras linguagens artísticas, visando, assim, à busca de uma organização integradora do conhecimento (BARBOSA, 1999).

A utilizaçáo de projetos de trabalho ${ }^{2}$ com fins pedagógicos torna-se um poderoso aliado na contemplação da grande quantidade de informação, indispensável para a formação global do indivíduo contemporâneo. Para trabalhar com o ensino de artes, é necessário ter um campo de conhecimento amplo, pois a área é de grande abrangência, e sem um conhecimento extenso o mediador fica impossibilitado de agir de forma interdisciplinar. Tal requisito implica em um conhecimento histórico e antropológico para promover uma aproximação com as diferentes culturas, épocas e lugares, um conhecimento estético e crítico para favorecer uma aprendizagem com base em análises e interpretaçôes, e o conhecimento prático, para a realização de produçóes com diferentes meios e recursos nos quais esses conhecimentos se projetem em novas produções, conforme coloca Hernández (2002, p. 56).

$\mathrm{Na}$ visão dos autores, há uma indicação de que é preciso, além da coerência na escolha do projeto ou na forma de ministrar os conteúdos, um conhecer que dará o suporte necessário para que o educador possa usar de atitudes criativas e ousadas, para despertar o interesse do educando, pois sem ele não ocorre o fluir do ensino aprendizado. Hargreaves (1998), apud Hernández (2002), pontua que, devido ao complexo contexto que se insere a educação, não é de se 
estranhar que a maioria dos docentes aceite propostas curriculares sem debatêlas criticamente. Isso porque a maioria dessas propostas oferece uma segurança aparente, diferente daquelas que precisam ser construídas a partir da necessidade do discente, baseadas muitas vezes em processos que reconhecem a incerteza do saber. Partindo desse princípio, ser criativo no ensino de artes passa a ser um desafio para o professor. Quando o educador opta por desenvolver um projeto de trabalho em busca do preenchimento de lacunas, sejam elas de conteúdos ou para gerar novas potencialidades e capacidades no educando, cria para si um grande desafio. Ainda, para que o projeto obtenha sucesso, é preciso promover uma mobilização na comunidade escolar, buscar envolver o aluno, a instituição e a família, sendo ele (professor) o mediador dessa tríade.

Quando se refere à escola, Vasconcellos (2006, p. 120) afirma que:

[...] é importante também desenvolver o senso de responsabilidade coletiva pela aprendizagem; não deixar tudo nas costas do professor, portanto, promover novos métodos para uma eficaz materialização do conhecimento passa a ser um desafio náo unicamente do professor em uma prática isolada, mas do conjunto que forma a comunidade escolar.

As iniciativas de trabalhar com projetos em prol de desenvolver a capacidade criadora para uma educaçáo globalizada, onde a escola participa ativamente, não são comuns, durante a pesquisa não foram encontrados registros, mas acredita-se que algumas escolas de ensino fundamental e de nível médio possam ter alguma disciplina de criatividade, incorporada ao currículo ou laboratório de criatividade, salvo em cursos de Ensino Superior. Considerando a importância da didática criativa para a educaçáo contemporânea, diversas atitudes devem ser tomadas pelas instituiçôes de ensino com a intençâo de favorecer mudanças na prática docente, como pontua Antunes (2003, p. 53):

Tornar o planejamento pedagógico dinâmico, destacando com clareza os objetivos para a exploração das capacidades, das competências e das múltiplas inteligências dos alunos. [...] Contar com a existência permanente de projetos significativos e relacionados as necessidades cotidianas que mobilizem a atenção e a energia dos alunos, que diversifiquem suas múltiplas linguagens, explorando 
alternativamente pintura, música, teatro, escultura, experiências científicas, esportes, danças e muitos outros.

Alencar (1996) reconhece também que os ambientes físicos, além dos psicológicos, influenciam no processo criativo, o ambiente de trabalho influencia positivamente ou negativamente nas atitudes dos funcionários, destaca a importância de boas condições de trabalho (sejam materiais ou psicológicas), são fatores determinantes nas organizações e instituiçóes, sendo que a capacidade criativa para o desenvolvimento de soluçóes e açóes passa pelo individual, mas é potencializada por influências externas, porém,vale lembrar que são subsídios e não regras para melhorar o processo criativo. Com base nos autores mencionados, constata-se que cabe às instituiçóes de ensino promover oportunidades através do incentivo, de práticas e açóes bem como conhecimento teórico, gerando suporte para que o professor possa ousar criativamente em suas práticas de ensino.

A família, apesar de em sua grande maioria, não estar preparada para a gestão do conhecimento dos filhos, tem um relevante papel apoiando e valorizando o estudo, a escola e os professores, também na cobrança da qualidade, considerando que a qualidade da aprendizagem não se mede pela nota recebida, mas sim pelo conhecimento adquirido. A maioria dos pais foi educada dentro dos moldes tradicionais da educação, nos quais a nota é o pagamento por alguma tarefa realizada, muitos professores e instituiçóes de ensino permanecem utilizando as mesmas práticas até os tempos atuais. A nota como objeto principal de desejo não permite ao aluno ficar motivado pelo prazer e pela necessidade consciente do aprender. $\mathrm{O}$ conhecimento produzido nesses casos acaba ficando em segundo plano, principalmente quando os objetivos não são claros e a proposta náo é desafiadora (VASCONCELLOS, 2008). Oferecer subsídios e desvincular a aprendizagem da nota, buscando diversificados métodos de avaliação, como por exemplo, por competência, a autoavalição, dentre outros, poderia ser uma importante contribuiçáo da família e da escola para as iniciativas e projetos propostos pelo professor.

Quanto ao aluno, não importa se possui grande ou pequeno potencial criativo, é essencial que sempre seja incentivado. Os estímulos para a mente, sob certos aspectos, identificam-se como estímulos para o corpo, não importa se aquele indivíduo não será um artista consagrado, mas devido ao encorajamento recebido e a prática desenvolvida, “[...] sempre crescerá significativamente em 
relação ao estágio em que anteriormente se encontrava." (ANTUNES, 2003, p. 46).

Quanto ao aluno, não importa se possui grande ou pequeno potencial criativo, é essencial que sempre seja estimulado. Neste caso, estímulos voltados a sua mente sob aspectos cognitivos e informacionais, e ao seu corpo no que diz respeito às sensaçóes. Ainda,não importa se aquele indivíduo será ou não um artista consagrado, mas devido aos recursos recebidos e a prática desenvolvida, "[...] sempre crescerá significativamente em relação ao estágio em que anteriormente se encontrava." (ANTUNES, 2003, p. 46).

Quando se pensa em projetos, deve-se considerar que a aceitação e a probabilidade de sucesso serão maiores quando houver clareza de objetivos, trabalho de mobilização e propostas desafiadoras.

\section{O projeto As Bruxas no Divã}

O objetivo deste artigo é fazer um relato e uma análise sobre o projeto As Bruxas no Divá, que foi a produção de um filme no Instituto Estadual de Educação (IEE), realizada por uma equipe que contou com a participação de alunos, funcionários e professores da Escola de Aplicaçáo (EDA) e do Curso do Magistério, no qual, a utilizaçáo da produçáo de cinema foi o elemento condensador de uma complexa e abrangente quantidade de informação a ser trabalhada.

O projeto buscou também oportunizar reflexões sobre conflitos existenciais. O filme aborda temas referentes a cada fase da vida, ou seja, a infância, a adolescência, a idade adulta e a velhice. Procurou, por meio de um texto sutil, evidenciar questôes antagônicas ora engraçadas ora sérias, constituindo-se em um convite para rir e também para refletir sobre as questóes expostas. Os dilemas comuns à vida de qualquer pessoa apresentados de uma forma lúdica permitiram a apreciação e a compreensão pelo público de todas as idades. O filme, que foi gravado em várias locais - principalmente nas dependências do IEE - mostra belas imagens do colégio. A participaçáo de um profissional da área da psicologia proporcionou um suporte teórico da psique humana e a partir dela trabalhamos todos os temas.

$\mathrm{O}$ projeto surgiu da necessidade de trabalhar as diversas linguagens artísticas de forma harmoniosa, sem prejudicar o conteúdo por causa do pouco tempo disponível, para contemplar um conjunto de conteúdos de 
Artes, sem fragmentação e superficialidade, comuns a práticas pedagógicas que pretendem abraçar grandes montantes de informação para construção de conhecimento.

A criatividade foi o elemento-chave para o desenvolvimento do projeto, sendo constantemente exercitada. A cada etapa novas soluçóes e alternativas eram requisitadas para a resoluçáo dos problemas. $\mathrm{O}$ ato criativo é citado por vários autores, é dividido em estágios que fazem parte da construção do processo de criação. Antunes (2003) cita cinco estágios, que são: a preparaçáo, a incubaçáo, o devaneio, a inspiraçáo, ou iluminaçáo, e a açáo. Analisando o desenvolver do projeto As Bruxas no Divã, percebe-se onde se localizam tais estágios e de que forma puderam se manifestar. Considerando que em algumas práticas mais complexas quando isoladas (analisadas separadamente) encontramos também todos os estágios citados. Esses estágios serão identificados e classificados, embasados nas pontuaçóes feitas pelo autor supracitado durante a descrição do processo de construção do projeto.

Para desenvolver este projeto, inicialmente apresentou-se a proposta de produzir um filme na escola, convidando os alunos a participarem, e conferindo a eles o papel decisório de como seria a natureza do filme. Por meio de debates em sala de aula e impulsionados por subsídios e sugestóes do professor, permitiu-se que as crianças se percebessem como parte integrante do processo, gerando assim o começo da mobilização. Localiza-se aqui o primeiro estágio, a preparaçáo, no qual se dá o reconhecimento de que um determinado problema que é digno de um estudo, com intuito de despertar uma solução criativa.

A natureza do filme foi definida como um conjunto de recortes de situaçóes comuns à vida de qualquer pessoa, e os dilemas que geralmente os indivíduos passam ao se deparar com situaçóes nas quais conflitos existenciais se apresentam. Para melhor compreensão por parte dos alunos, foi trabalhado o conceito de "conflitos existenciais". Dessa maneira, a apreciação de imagens, filmes e textos passaram a fazer parte do percurso, sendo que depois da análise do material os alunos registraram em desenhos, textos e/ou narrativas o que significava para cada um deles o tópico sugerido para cada aula.

A produção deu início com a elaboração do roteiro. Esse foi um momento de grande efervescência de ideias. Segundo Antunes (2000), é importante evitar censuras, críticas ou frustraçôes nesse momento, a mediação imparcial do professor se faz indispensável, ou seja, devido a sua experiência, pode indicar caminhos que ajudarão no processo criativo e auxiliar no desbloqueio do ato 
de criar, ocasionado em situaçóes anteriores nas qual o aluno sofreu alguma ação recriminadora.

Existem vários tipos de bloqueios que interferem significativamente nas atitudes do indivíduo, tornando-o menos criativo, entre outros problemas gerados. Esses bloqueios foram classificados por Adams (1994) como:

- Bloqueios Mentais - são frutos de uma aprendizagem que começa muito cedo em nossa vida, a partir dos ensinamentos que a sociedade nos transmite: negar emoçóes, resguardar a curiosidade, evitar se expor, não correr riscos, evitar o fracasso, gerando sentimentos de culpa, vergonha e constrangimento.

- Bloqueios de Percepção - diz respeito à dificuldade de isolar o problema, entende-lo claramente em si ou a falha em usar todos os mecanismos sensoriais, julgar ao invés de gerar ideias, incapacidade de "incubar" uma ideia.

- Bloqueios Emocionais - o homem cria segundo impulsos internos e parte da criatividade ocorre numa regiáo da mente que se encontra abaixo do nível consciente. Ela flui melhor na ausência de neuroses. Apatia, baixa tolerância às mudanças, medo de assumir riscos, apego excessivo à ordem e segurança, inabilidade de tolerar a ambiguidade, medo de parecer ridículo, medo de fracasso e de cometer erros, sentimentos de inferioridade.

- Bloqueios Culturais - tabus e falta de humor na resoluçáo de problemas, reação e intuição, pensamento dos lados direito e esquerdo do cérebro, tradição e mudança. O problema surge quando os indivíduos são presos à tradição negando a necessidade e o desejo de mudança.

- Bloqueios Ambientais - são causados pela intransigência e pelo autoritarismo, protecionismo e paternalismo, falta de integraçáo, falta de apoio para se colocar novas ideias em ação, falta de estímulo aos indivíduos, falta de confiança (roubo de ideias e ciúmes).

- Bloqueios de Intelecto e de Expressão - impede que a pessoa adquira informaçôes balanceadas e pertinentes, habilidade inadequada de linguagem e a imprecisão na expressão verbal, impedindo a comunicação e o entendimento. 
A criação é um processo natural, é próprio da criança desenhar, pintar, dançar, representar, brincar, entre outras atividades. A forma como essas atitudes vem sendo trabalhada na escola favorece o abandono de certas atividades estéticas e das múltiplas linguagens presentes na infância (FRITZEN; MOREIRA, 2008). Tais atividades deixam de existir, não são mais encontradas nos mesmos indivíduos quando adultos, reflexo dos bloqueios sofridos. Estes não recebem mais as atividade artísticas com o mesmo entusiasmo de quando eram crianças. A recepção das atividades propostas pelo projeto As Bruxas no Divã foi medida pelo empenho dos alunos na criação, as crianças e os adultos passaram a trazer muitas sugestôes de casa, o que evidenciava o diálogo com familiares, envolvimento e reflexão sobre os temas propostos. Vários temas pertinentes à vida do ser humano foram trabalhados, como a solidão, a vaidade, a competição, o trabalho e as questốes financeiras, os relacionamentos afetivos (namoro, amizade, ciúmes etc.), a velhice, o preconceito, a separação (de amigos, divórcio dos pais), as perdas, os estereótipos, entre muitos outros, a fim de entender como os indivíduos constroem-se a partir da inserção social e como se tornam agentes da constituição de sua própria realidade.

O objetivo da contextualização é desenvolver a percepção de que a ficção proposta pelo filme que estava sendo produzido é uma releitura da realidade que se vive, uma produção cultural. Considerando que a arte é um trabalho do pensamento, entender a arte como conhecimento implica em refletir sobre alguns aspectos do processo de criação, que acontece a partir do conhecimento que existe das representaçôes da relação homem-mundo (CHAUÍ, 1994). Essa relação homem-mundo está ligada à representação social que, segundo Moscovici (1978, p. 35), "[...] é o processo de assimilaçáo e construçáo da realidade pelos indivíduos”. Com esse conceito, ele estabelece uma relação entre indivíduo e sociedade, náo considerando a representaçấo social necessariamente como uma imposiçáo do contexto, mas um reflexo dele, tendo como base a realidade. Para os alunos, as representaçóes fictícias desenvolvidas para o filme passam a ser uma oportunidade de se posicionarem perante o mundo, a partir de seu histórico e de seus conhecimentos.

Nesse momento do projeto em que as reflexões foram instigadas, a incubaçáo aparece de maneira sutil. Esse estágio caracteriza-se por ser o momento em que tudo que se refere ao problema está armazenado no nível inconsciente, e onde as ideias estão sendo processadas. Segundo Antunes (2003, p. 37), nesse momento o professor não tem de intervir, mas deve ajudar o aluno 
a desbloquear a sua criatividade, libertando-se de mecanismos consciente de autocensura e autocrítica, "[...] a incubação é importante porque os subterrâneos da mente guardam infinitas coleções de dados, fatos, referências e pensamentos, que são inconscientemente freados pelo racional e, nesse estágio, vai-se a esses subterrâneos buscar elementos que auxiliam o ato criador".

A preocupação na criação da identidade das personagens para dramatizar as situaçôes propostas foi um dos desafios. A incubação se deu nesse momento como um período de aglutinação e combinação de ideias, era preciso criar personagens que fossem facilmente identificadas do começo ao final da história, pois as mesmas personagens seriam representadas por atrizes diferentes em distintas idades e fases da vida. Para evitar possíveis falhas na identificação, foi elaborado um perfil com as posturas, os gestos, as reações e as falas etc., além, das questóes físico-estéticas que se repetiam em todas as protagonistas.

A tentativa de se diferenciar também ocorre na vida real, considerando que as representaçôes sociais são culturalmente construídas, sendo uma forma de conduta em que as pessoas também criam e vivem representaçóes individuais. Reforçar a identidade passa então a ser uma forma se diferenciar onde o indivíduo procura por meio de elementos visuais e comportamentais, individualizar-se dentro da grande massa humana em que está inserido. É a busca de uma identidade dentro da coletividade. As representaçóes individuais (visuais e comportamentais) podem ratificar ou não as representaçóes socialmente constituídas (padróes de comportamento e de aparências, relacionados a estilo de vida e a condição social,)

Desse modo, o projeto buscou fazer com que o discente refletisse sobre sua própria identidade. Com esse propósito, os alunos foram estimulados a levar para as aulas objetos pessoais - como livros, fotos, roupas etc. - que remetessem a sua própria história, constituindo um exercício de autoconhecimento. Muito do material e as narrativas sobre eles foram utilizados na construçáo do roteiro e como elementos de cenário. Materializou-se nesse momento do projeto o terceiro estágio, o devaneio.

O devaneio caracteriza-se por um momento geralmente de curta duração, em que o problema é deixado de lado propositalmente, para em seguida ser retomado com maior vigor e com as ideias já organizadas para passar para o quarto estágio, que é a inspiração, ou a iluminaçáo.

Em sala de aula, analisavam-se os materiais e inseriam-se novos subsídios a fim de aguçar os olhares dos alunos para a exploração e a compreensão, além 
da sua contextualização e da análise crítica. A criação da história a ser contada teve origem no universo do cotidiano dos alunos, professores e funcionários. A comunicabilidade oral foi estimulada principalmente durante as narrativas e na interação da equipe, pois é uma ferramenta voltada a troca de experiências. $\mathrm{O}$ saber se expressar bem oralmente e a desenvoltura são mais do que qualidades do indivíduo, são necessidades contemporâneas, cada vez mais valorizadas na atual era da comunicação e informação.

No quarto estágio, o da inspiraçáo ou da iluminaçáo, as ideias já estavam propostas, era o momento em que já se sabia o que fazer e como fazer, a organização passava a ser o foco de atenção. $\mathrm{O}$ conceito de tempo também foi trabalhado por meio da evolução e das transformações que biologicamente e socialmente acontecem na vida das pessoas, isso facilitou o encaixe das ideias. No filme, essas transformações são interpretadas por dois personagens centrais da história, as bruxas Joseane (Jô) e Gabriela (Gab).

Dramatizaçóes sobre os temas abordados fizeram parte de todo processo, sempre seguidas de debates, muitas vezes pontuados por relatos de experiências pessoais vividas em determinado contexto histórico relacionado ao tema trabalhado. Os alunos ampliaram seu leque de conhecimentos e compreensão. A preferência por temas sociais, políticos e econômicos foi levada em conta, mas o foco principal ficou na velhice e na desmistificação de estereótipos (estereótipo da bruxa, visto que esta foi humanizada durante a construção da história). Segundo Alencar (1996), nesse estágio é importante que o professor esteja atento para que não se volte ao estágio do devaneio, devido às ideias novas que continuarão surgindo desviando o foco de atenção.

O filme que tem como base dois personagens que são bruxas, promoveu uma desmistificação do estereótipo em relação ao estético e ao seu perfil tradicional, pois geralmente quando se fala em bruxas imagina-se uma mulher velha com uma verruga na ponta do nariz (esse estereótipo é utilizado ao longo dos tempos e se faz ainda presente no imaginário coletivo), considerando que a imagem da velhice é diretamente relacionada à imagem das vovós, que nada tem a ver com as bruxas más de outrora. Então, gerou-se o questionamento: de onde vem essa ligação da velhice com a ideia de bruxa feia e má? Por essa e muitas outras questões, a pesquisa se fez recorrente durante todo o projeto. O conhecimento é necessário para estabelecer ligações e encontrar soluçôes criativas (ALENCAR, 1996). O problema de como representar a bruxa resultou em uma pesquisa sobre o próprio histórico da bruxa ao longo da história da 
humanidade, o que proporcionou a satisfação da curiosidade e o alívio da inquietude positiva diante do dilema instaurado.

Sendo a velhice um dos focos centrais, foi a partir dela e das lembranças de uma das personagens que a história do filme se desenvolve, perpassando por um montante de conflitos existenciais comuns à vida de qualquer pessoa, em diferentes períodos, desde a infância até o amadurecer de sua vida. Mesmo sendo um tema antigo, a velhice, recorrente na literatura e no cinema infantil e adulto, é representada de formas diferentes, devido a fatores sociais, culturais, políticos e econômicos. Por estar retratado de forma multifacetada, o tema torna-se de grande potencial para estudos, que investiguem as diferentes representaçóes de senilidade nos textos literários, nos filmes e nos conceitos já estabelecidos pelas crianças dos tempos correntes durante sua formação.

O tema foi discutido plenamente, o que enfatiza o interesse do público infantil e adulto por ele, as ideias geradas possibilitariam diversas produçóes distintas sobre a velhice e o que está em sua volta. Fato esse que reforça a presença do professor na mediação do processo criativo, para que seu desenvolvimento não volte ao estágio de devaneio.

$\mathrm{Na}$ experiência realizada, percebe-se que tanto crianças como adultos, apesar da extrema valorização da informação e com as mudanças tecnológicas constantes, preservam a imagem da velhice como fonte de sabedoria, tanto na ficção como na vida real. As crianças e os idosos sấo partes de um cordão, cada um em uma extremidade, as pontas quando unidas constroem um círculo, essa junção fomenta a imaginação despertando a criatividade em torno de histórias de cumplicidade estabelecida, onde molecagens criam um universo à parte, favorecendo o exercício de açóes e ideias criativas.

Falas populares, como: "os pais servem para educar os filhos e os avôs para deseducá-los", materializam a afetividade e o permissivo entre avós e netos. No cotidiano a confecçãode doces, a construção de brinquedos e concessóes para as crianças estabelecem laços muito significativos, pois a afetividade é o elo entre infância e velhice. Isso faz a união perfeita, quem tem muitas memórias a reviver e tempo para contá-las - avós - com quem está ávido por ser e ter memórias e tem tempo para ouvi-las - netos - sendo que, a ficção imita a realidade, nos deparamos constantemente com esse fato que é explorado de maneira recorrente na literatura e no cinema. Segundo Fritzen e Moreira (2008), os filmes trazem mensagens, noções, conceitos, concepçóes e valores que vão desde a visão do bem contra o mal,também conformismo, submissóes, relações de poder, resistências, 
até padróes de comportamento, queevidenciam arquétipos e estereótipos, tais características foram trabalhadas na construção do filme produzido pela escola e são facilmente identificadas. Nas produçôes profissionais que são consumidas geram identificação e reprodução por quem assiste a essas películas.

Pedagogicamente explorada, a ficção pode ser transformada como produção cultural, na medida em que realça os signos de uma sociedade e determina limites entre o desejável e o indesejável. Por isso, tornam-se elementos mais significativos para a formação do ideário dos indivíduos, porque atuam na construção, difusão e alteração das mensagens, das noçóes conceitos, das concepçóes e dos valores. A autora complementa pontuando que a utilização de filmes (seja na produção ou na simples contemplação) é um importante instrumento didático, pois tem a capacidade de transportar os indivíduos para além de suas fronteiras, o que acaba interagindo com os diferentes saberes, indenidades, crenças e visōes de mundo de grandes contingentes de atores sociais.

Com essa dimensão, as representaçôes sociais podem manter e/ou reforçar uma posição determinada por um grupo específico dominante ou até mesmo transformá-las, apresenta-se assim a força da produção criativa, da imagética e da expressividade do cinema.

\section{A difícil tarefa das escolhas}

Diante número de informaçóes, ideias e possibilidades desenvolvidas pelo poder criativo estimulado, precisou-se fazer escolhas, pois não era possível contemplar o montante produzido. Para não gerar frustrações e possíveis bloqueios, as escolhas foram feitas pelo grande grupo de forma democrática, por meio de votaçóes. A escolha do título para o filme produzido no colégio, As Bruxas no Divã, deu-se em função de os personagens principais representados serem duas bruxas, pelo formato em que foi desenvolvido e também pelas situaçôes nele apresentadas. $\mathrm{O}$ formato busca estabelecer afinidades com os personagens representados, algumas cenas foram elaboradas de forma que o personagem fale dirigindo-se diretamente para a câmera, como se estivesse dialogando com o espectador do outro lado da tela, gerando assim uma cumplicidade entre ambos. O texto reforça a ideia de que a personagem está confidenciando seus dilemas, como se estivesse diante de alguém próximo, como uma pessoa amiga, com a qual se compartilha questóes íntimas ou no divã de um analista. 
Para serem dramatizadas, foram escolhidas as situaçóes e os dilemas mais comuns e recorrentes, para que o filme obtivesse um caráter mais universal. A escolha caracterizou-se por ser um momento em que o educando pode exercitar seu direito de escolha, advogar em prol de seu ponto de vista e administrar respeitosamente os posicionamentos e as ideias contrárias. $\mathrm{O}$ processo de produção cinematográfica, mesmo amadora (que é o caso), quando em grupo torna-se elemento significativo, pois, gera muitas vivências onde se percebe as responsabilidades de um trabalho em equipe, sendo preciso saber ouvir e também expressar ideias.

\section{A materialização do projeto}

Constatou-se entusiasmo durante o processo de construção do filme, porém um maior fascínio foi percebido em crianças e adultos no momento em que a linguagem cinematográfica passou a ser objeto de estudo. Esse momento caracteriza-se como o estágio de açáo". Antunes (2003, p. 38) refere-se como o momento do processo de criaçáo em que os alunos se mostram apaixonados pelo o que estáo desenvolvendo, pois a mente criativa libera o fluxo da ideia para que as mãos ou o corpo execute, "É o momento em que a ideia necessita ser trazida a realidade”. Era o filme que começava a se materializar.

A não linearidade do filme pode-se citar como um desafio encontrado. Essa característica exigiu um cuidado maior na organização das tomadas e das locaçôes (que evidenciavam os diferentes períodos e locais onde as cenas aconteceriam). Foram editadas duas versóes, a original é a mais longa, na qual se contempla uma quantidade maior de temas, apresentada de forma não linear. Nesta, a compreensão do todo se dá ao término do filme, sendo assim, este corporificar-se na medida em que as lembranças vão sendo contadas, fora da sequência natural da vida da personagem, mas que se justifica devido a sua idade avançada, por isso os fatos váo sendo narrados como vagas recordaçóes entre lapsos de memória. A outra versão é resumida, apresenta-se de forma linear pra uma melhor compreensão do público infantil.

A maior dificuldade na realização do projeto As Bruxas no Divã encontrouse no estágio da açáo, na finalização do projeto, na edição, no que tange à parte técnica. A falta de equipamentos adequados e de experiência na sua utilização fez a equipe adaptar criativamente novos elementos e tecnologias similares. 
A criatividade se fez presente durante todo o processo, pois desenvolver a criatividade nos alunos é desenvolver um conjunto de potencialidades.

Segundo Hermann (1990 apud VIRGOLIM; FLEITH; PEREIRA, 1999), a criatividade é um processo que envolve o cérebro como um todo, esse fato vem ao encontro das práticas pedagógicas para potencializar a aprendizagem e o desenvolvimento do educando em seu todo, implica a habilidade de desafiar suposiçôes, reconhecer padrōes, ver de novas maneiras, fazer conexóes, arriscarse, e 'agarrar as chances'.

Foram feitos uso de elementos das diversas linguagens artísticas como percepção de estruturas rítmicas, transformação de histórias em roteiro, expressão corporal, música, desenho, modelagem, pintura, confecção de figurinos e fotografia. A interdisciplinaridade ocorreu espontaneamente, uma vez que uma gama de conhecimentos não só de artes estava sendo trabalhado, mesmo sem os alunos se darem conta disso.

Para a construçấo das cenas, foram realizados debates constantes, nos quais eram discutidos todos os elementos a ela pertencentes, cada grupo utilizou uma ou mais linguagens artísticas em seus processos de criação. Surgiram, então, pequenas peças de teatro, propostas de cenários em desenhos e maquetes amadoras, histórias em quadrinho para definir capítulos do filme, músicas para a trilha sonora, entre outros. Para Hernández (2002), faz-se necessário criar esse tipo de vivência para ajudar a compreender a realidade, a continuar o processo de examinar os fenômenos que nos rodeiam de maneira questionadora e construir "visóes" e "versões" alternativas não só diante das experiências cotidianas, mas também diante de outras distanciadas da vida presente da criança e do adulto. A utilizada didaticamente, a ficção, pode potencializar a transformação das informaçôes em conhecimento através desse fascínio que exerce sobre os indivíduos e também das vivências oportunizadas em sua produção.

\section{Considerações}

É importante considerar que a literatura e o cinema infantil só foram considerados algo importante recentemente, pois eram percebidos somente como uma recreaçáo, desconsiderando o fato de estes serem formadores da consciência da vida cultural das sociedades em que estavam inseridos (MASCARELLO, 2006), desconsiderando o poder desses instrumentos para a informação e produção de conhecimento, bem como para a manipulação 
dos indivíduos ainda em formação. O mesmo autor complementa que esse cinema esteve durante praticamente todo seu percurso histórico a serviço de ratificar as representaçôes sociais canônicas e estereotipadas, que valorizavam os princípios ocidentais, sobretudo europeus. O capitalismo, a cor branca, a religião católica, a heterossexualidade e a busca da eterna juventude, sendo essa última uma das responsáveis pela manutenção do estereótipo da mulher idosa com a bruxa e com o feio.

Alencar (1996) emerge a observação de que a atual cultura cinematográfica e as mídias de forma geral estão muito preocupadas com a criança-consumidora e a escola com a criança-aluno. É preciso que haja uma preocupação com o sujeito criança-criança. Assim, pensar o cinema na escola e a educação como formação de cultura implica a adoção de uma postura crítica e de capacidades expressivas para avaliar ética e esteticamente o que está sendo oferecido pelos filmes usados dentro e fora da escola, bem como oferecer subsídios para que o próprio aluno saiba exercer corretamente suas escolhas.

As Bruxas no Divã teve uma pré-estreia em 15 de dezembro de 2007 no auditório Pedro Bosco no IEE, contou a presença dos familiares, amigos, funcionários, professores e convidados especiais. O DVD está à disposição para empréstimo na videoteca do IEE 3 .

\section{Conclusão}

Sendo o desafio do professor de Artes, de ousar criativamente na sua prática de ensino, conclui-se que ao propor um projeto que venha de encontro aos anseios do grupo envolvido, que gere uma mobilizaçáo e que envolva a comunidade escolar, produz-se maiores chances para vencer o desafio. A construção do filme As Bruxas no Divã proporcionou vivências, nas quais se constatou a importância do ser criativo na produçáo de ideias e novas possibilidades. O conhecimento foi desenvolvido por meio das informaçôes mediadas, oportunizando descoberta e promovendo capacidades e novos saberes (através das ligaçóes cognitivas). O projeto realizado vem de encontro às novas formas de ensinar e da busca de uma prática de ensino e aprendizagem adequadas ao indivíduo contemporâneo.

Averiguou-se que o aluno devidamente estimulado reage positivamente às atividades propostas e que o aprendizado se dá de maneira harmoniosa e prazerosa. Facilitando a superação do desafio do professor de Arte em 
promover um conhecimento amplo (devido à necessidade de contemplar as diversas linguagens artísticas), sem cair na superficialidade e fragmentaçâo, essa constatação se dá ao observar o montante de conteúdos, técnicas, conceitos, entre outros que foram trabalhados de forma interdisciplinar, agregando outros saberes vinculados a outras disciplinas, em torno de um único objetivo, a elaboração do filme proposto.

A criatividade surge de um processo natural, mas depende do conhecimento para que se estabeleçam relações a fim de chegar ao resultado esperado (embasado em autores citados nesse artigo). Essa pontuação se mostrou verdadeira, pois, para criar o filme muitos saberes foram necessários e também muitos outros foram construídos no decorrer do processo. Ao analisar o processo de construção, percebeu-se os estágios da criação, a preparação, a incubação, o devaneio, a inspiração, ou iluminaçáo e a ação, bem como a necessidade de o ambiente favorecer o ato de criar. Por meio de relatos de participantes, também é fácil identificar possíveis bloqueios e açôes desbloqueadoras do projeto, a fim de libertar para um fluir da criatividade.

Por meio de relatos de professores, constatou-se na parte didática que as crianças evoluíram em sua aprendizagem em todas as disciplinas, pois o incentivo desenvolveu a prática da pesquisa e o comprometimento com o estudo, tornando-se mais responsáveis com seus deveres. Averiguou-se que reutilizaram as pesquisa e muito do que se aprendeu durante o projeto, principalmente sobre conceitos de tempo e espaço, expressão corporal, apreciação da arte de escrever, desenvolvendo assim a capacidade de lidar com as palavras, com as imagens e com a estética.

Conclui-se que projetos como este são necessários, pois além de trabalhar as diversas linguagens artísticas de uma maneira lúdica e eficaz, desenvolveu nos alunos o respeito aos diferentes saberes. Tem-se então uma forma de valorizar as múltiplas inteligências, de educar para ver, analisar, compreender e posicionar-se frente aos acontecimentos, às transformaçóes, aos fatores sociais, aos problemas $\mathrm{e}$ às realidades distanciados no espaço e no tempo (das crianças, adolescentes e adultos). Com base em atividades realizadas posteriormente, percebeu-se mudanças positivas com relação aos trabalhos em equipe, os alunos tornaram-se mais respeitosos entre si, mais colaborativos, além de desinibidos.

Sobre a temática escolhida, percebeu-se que muito há de se fazer para se erradicar estereótipos junto ao público infantil. Sendo assim, é preciso fazer escolhas coerentes de leituras e filmes. Indicar livros e filmes que sugerem 
uma velhice sempre feliz e sem problemas não leva a uma visão crítica do que representa a velhice para a sociedade brasileira, bem como utilizar-se de livros e filmes que identificam a terceira idade como algo feio (imagem da bruxa velha feia e má das antigas histórias e contos), colabora para a manutenção da imagem negativa, que a sociedade atual é reforçada pela busca eterna da jovialidade, agravando ainda mais esse problema.

Percebe-se que, de um modo geral, embasado no corpus estudado, os valores apresentados atualmente pela literatura e pelo cinema infantil na representação de pessoas idosas estão construindo um novo imaginário social em que a velhice aparece com conotaçóes na sua grande maioria positivas, sempre estabelecendo uma relação muito próxima com a infância, paralelamente mudaram também as visóes e versóes sobre as bruxas.

A literatura e o cinema infantil podem ser um instrumento para a sensibilização da consciência, para a expansão da capacidade de analisar o mundo, sem estar a serviço de qualquer interesse. Portanto, desmistificar e retificar erros cometidos passa a ser um desafio, é importante considerar que se está formando futuras geraçóes e o que se semeia hoje é o que se colhe amanhã.

\section{Notas}

1 Segundo Barbosa (1999), a polivalência caracteriza-se no ensino de artes como a tentativa de contemplar as diversas linguagens artísticas. Geralmente essa prática pedagógica fracassa devido à grande abrangência de conteúdos da área e pouco tempo de carga horária para ministrá-los.

2 Projeto de trabalho é caracterizado por Hernández (2002) como uma atividade envolvente sobre um tema escolhido que une a teoria e a prática no ensino de uma forma interdisciplinar.

3 Instituto Estadual de Educação, Avenida Mauro Ramos, 275, Centro, Florianópolis/SC. 


\section{REFERÊNCIAS}

ADAMS, James L. Ideias criativas: como vencer seus bloqueios mentais. Rio de Janeiro: Ediouro, 1994.

ALENCAR, Eunice Soriano de. A gerência da criatividade. Sáo Paulo: Makron Books, 1996.

ANTUNES, Celso. A Criatividade em sala de aula. Petrópolis, RJ: Vozes, 2003.

ANTUNES, Celso. Jogos para a estimulação das múltiplas inteligências. 8. ed. Petrópolis: Vozes, 2000.

BARBOSA, A. M. T. B. A imagem do ensino da arte. 4. ed. São Paulo: Perspectiva, 1999.

CHAUÍ, Marilena. Universo das artes. In: CHAUÍ, Marilena. Convite a Filosofia. São Paulo: Ática, 1994.

FRITZEN, Celdon; MOREIRA, Janine (Org.). Educação e arte: as linguagens na formação humana. Campinas, SP: Papirus, 2008.

FUSARI, Maria F. R.; FERRAZ, Maria Heloisa C. T. Arte na educação escolar. São Paulo: Cortez, 2001. (Coleção Magistério 2o grau; Série formação geral).

HERNÁNDEZ, F. Cultura visual, mudança educativa e projeto de trabalho. Porto Alegre: Artes Médicas, 2002.

LAPLANCHE, Jean. Vocabulário da psicanálise. São Paulo: Martins Fontes, 2001.

MACHADO, Ana Maria. Bisa Bia, bisa Bel. Rio de Janeiro: Salamandra, 1985.

MASCARELLO, Fernando. Historia do cinema mundial. Campinas, SP: Papirus, 2006.

MOSCOVICI, Serge. A representação social da psicanálise. Rio de Janeiro: Zahar, 1978.

VASCONCELLOS, Celso dos Santos. A (in)disciplina: construção da disciplina consciente e interativa em sala de aula na escola. São Paulo: Libertad, 2006.

PERSPECTIVA, Florianópolis, v. 30, n. 2, 531-551, maio/ago. 2012

http://www.perspectiva.ufsc.br 
VASCONCELLOS, Celso dos Santos. Avaliação da aprendizagem: práticas de mudança. São Paulo: Libertad, 2008.

VIRGOLIM, A. M. R; FLEITH, D. S.; PEREIRA, M. S. N. Toc, Toc... Plim, plim! Lidando com as emoçóes, brincando com o pensamento através da criatividade. 5. ed. Campinas, SP: Papirus, 1999.

WURMAN, R. S. Ansiedade de informação: como transformar informação em compreensão. São Paulo: Cultura, 1991. 


\section{Halloween en el sofá: el reto de ser artes creativas y se atreven en la educación}

\section{Resumen}

Este artículo presenta el proyecto "Las brujas en el diván”, que consiste en la producción de una película en el Instituto de Educación del Estado (IEE), en la escuela pública del Estado de Santa Catarina. En el se introdujo el lenguaje cinematográfico en la educación infantil, contribuyendo en el proceso de enseñanza y aprendizaje del arte. El objetivo de este proyecto fue desarrollar una experiencia dentro de las diversas formas artísticas como el teatro, artes visuales, música, danza y otras ramificaciones, así como afinar la reflexión sobre las preguntas existenciales de la vida y mejorar el proceso creativo. Para la realización de la película se utilizaron diversos saberes así como nuevas tecnologías seguidas de la observación y análisis del aprovechamiento que los alumnos obtuvieron durante la práctica pedagógica. El elemento motivador en los participantes fue la literatura y la producción de cine amateur infantil, que resultó ser una forma de comunicación apta para establecer interdisciplinaridad con varias áreas del conocimiento de forma creativa y harmoniosa.

Palabras clave: Artes - Educación. Cine - Medios de Enseñanza. Desarrollo de la Creatividad.

\section{Witches on the divan: the challenge of being creative and daring in art education}

\section{Abstract}

This article reports on the "Witches on the Divan", project that consists in the production of a film at the Instituto Estadual de Educação (IEE), a school in the Santa Catarina state educational system. It introduces cinematographic language to elementary education, contributing to the teaching and learning of arts. The purpose of the project was to develop an experience within various artistic languages, such as theater, visual arts, music, dance and others, and to sharpen the reflection about existential questions of life and give potential to creative processes. Various kinds of knowledge were used to make the film, as well as new technologies, followed by observation and analysis of how students used this proposal for pedagogical practice. The motivating element of the research was the literature and production of amateur children's cinema, which proved to be a form of communication capable of establishing interdisciplinarity among various fields of knowledge in a creative and harmonious manner.

Keywords: Arts - Education. Cinema - Educational means. Development of creativity. 
Márcio Luiz Bess

E-mail: marciobess@hotmail.com

Marcelo Luis Rossa

E-mail:magnum-opus@uol.com.br

Tarcísio Vanzin

E-mail: tvanzin@yahoo.com.br

Recebido em: 31/8/2010

Versão final recebida em: 4/3/2011

Aprovado em: 9/3/2011 